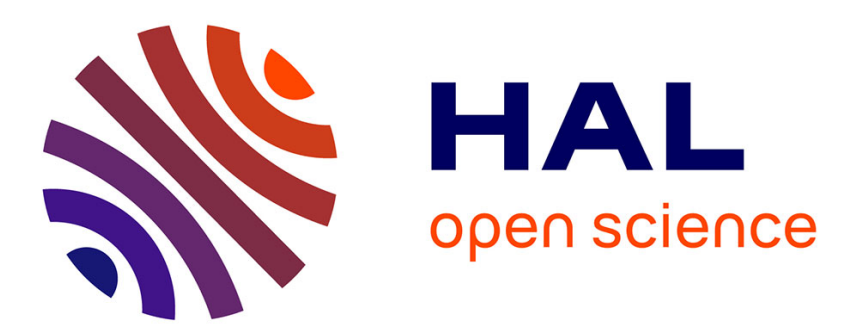

\title{
Investigations on an electroactive polymer based tunable Helmholtz resonator
}

\author{
Ahmed Abbad, Kanty Rabenorosoa, Morvan Ouisse, Noureddine Atalla
}

\section{To cite this version:}

Ahmed Abbad, Kanty Rabenorosoa, Morvan Ouisse, Noureddine Atalla. Investigations on an electroactive polymer based tunable Helmholtz resonator. Smart Structures + Nondestructive Evaluation, Mar 2017, Portland, United States. hal-02392526

\section{HAL Id: hal-02392526 \\ https://hal.science/hal-02392526}

Submitted on 4 Dec 2019

HAL is a multi-disciplinary open access archive for the deposit and dissemination of scientific research documents, whether they are published or not. The documents may come from teaching and research institutions in France or abroad, or from public or private research centers.
L'archive ouverte pluridisciplinaire $\mathbf{H A L}$, est destinée au dépôt et à la diffusion de documents scientifiques de niveau recherche, publiés ou non, émanant des établissements d'enseignement et de recherche français ou étrangers, des laboratoires publics ou privés. 


\title{
Investigations on an Electroactive Polymer based tunable Helmholtz resonator
}

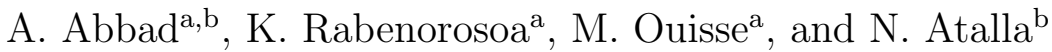 \\ ${ }^{a}$ Univ. Bourgogne Franche-Comt/CNRS/ENSMM/UTBM - FEMTO-ST Institute, 24 rue de \\ lpitaphe, 25000 Besanon, France \\ ${ }^{\mathrm{b}}$ GAUS, Department of Mechanical Engineering, Universit de Sherbrooke, Sherbrooke, QC \\ J1K 2R1, Canada
}

\begin{abstract}
A Helmholtz resonator is a passive acoustic resonator classically used to control a single frequency resulting from the cavity volume and the resonator neck size. The aim of the proposed study is to present a new concept and strategy allowing real-time tunability of the Helmholtz resonator in order to enhance acoustic absorption performances at low frequencies $(<500 \mathrm{~Hz})$. The proposed concept consists in replacing the resonator rigid front plate by an electroactive polymer (EAP) membrane. The first proposed strategy consists on a change in the mechanical properties of the membrane resulting from the applied electric field. This induces a resonance frequency shift. A second strategy is based on a well-located spring, which could direct the membrane deformation following the axis of the resonator to obtain a cavity volume variation. Both strategies allow variation of the resonance frequency of the device. Experimental measurements are performed to determine the potential of this concept for improvement of low-frequency performances of the acoustic devices.

Keywords: Noise reduction, Tunable Helmholtz resonator, Electroactive polymer (EAP), Absorption efficiency.
\end{abstract}

\section{INTRODUCTION}

Helmholtz resonators (HR) are devices designed to cancel a single frequency, whose value is related to their geometrical dimensions. ${ }^{1-3}$ The high impedance produced by the cavity and the neck attenuates the incident wave. ${ }^{4}$ Large values of Transmission Loss (TL) and absorption $(\alpha)$ result from the blocked incident wave. ${ }^{5-7}$ Helmholtz resonators are proposed as a solution to control the acoustic performances of a structure such as an aircraft fuselage. ${ }^{8,9}$ There are multiple means of integrating passive resonators into an aircraft wall to control its acoustic TL. ${ }^{10,11}$ These passive resonators being efficient only at tuning frequency, solutions based on active and semi-active strategies allowing real time controllability have emerged. Several attempts can be found for designing adaptive HR exhibiting tunability through the adjustment of the resonance frequency. Among others, a HR with a variable volume is presented in. ${ }^{12}$ A DC motor controls a movable wall, which modifies the cavity volume. An interesting concept based on an in-situ, tunable-impedance of an electromechanical compliant-backplate HR has been proposed. ${ }^{13}$ Results obtained by ${ }^{14}$ show that two resonance frequencies were obtained resulting from the HR and the backplate vibration. The diaphragm geometry has a significant influence on the TL because of changes in effective cavity volume.

Electroactive polymers (EAPs) have recently emerged as smart materials with various potential and distinct industrial applications such as actuators, ${ }^{15}$ artificial muscles ${ }^{16}$ and the design of innovative acoustic resonators exhibiting real-time controllability. EAPs can be divided into two major categories based on their activation mechanism: driven by electric field referred as electronic and ionic which requiring diffusion of ions. ${ }^{17}$ An EAP material is composed of a Dielectric (DE) membrane (in our case the 3M VHB 4910) sandwiched between two compliant electrodes. The applied voltage reduces the material thickness and changes its stiffness. An area expansion is then observed. This type of membrane offers interesting mechanical and electrical properties. Such membranes exhibit lightness, highly energetic density, high strain rate up to $400 \%$, and also fast response time $(<1 \mathrm{~ms}){ }^{18}$ The acoustic performances of a duct silencer formed with a DE membrane and back cavity were experimentally investigated by. ${ }^{19}$ Results show that the obtained resonance peaks could be adjusted and depends on the pre-stretch ratios $(\lambda)$ of the DE membranes. A metamaterial comprising an array of resonators 
was investigated by. ${ }^{20,21}$ The peaks in the TL curves can be shifted towards lower frequencies when the applied voltage increases.

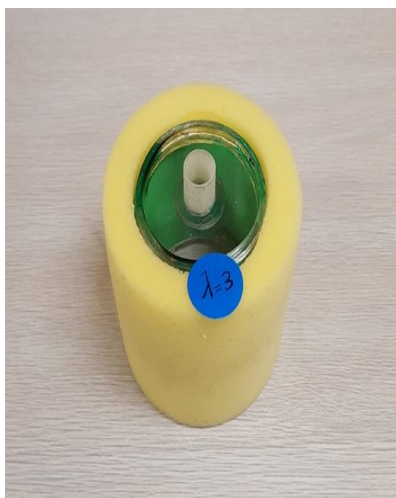

a) HR1: Passive

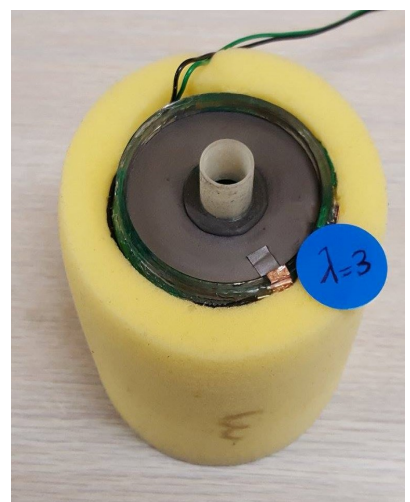

b) HR2: Active

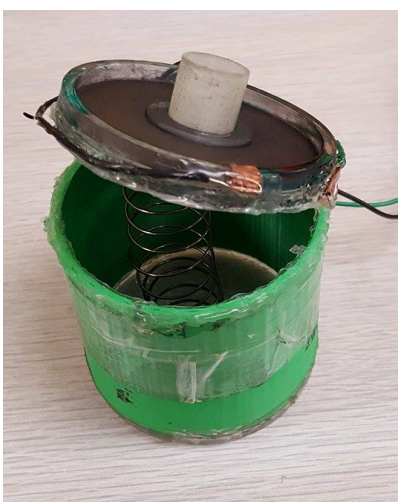

c) HR3: Variable volume

Figure 1. Studied Helmholtz resonators

In this study, numerical and experimental investigation of a tunable HR using an EAP membrane is studied. Three different configurations are presented. Acoustic absorption $(\alpha)$ of a passive front-wall HR integrated in an ultralight melamine foam matrix is first studied. A numerical model is proposed only in the case of passive membrane. Results are compared with the experimental. The second device is a tunable HR. The integrated membrane is activated by an applied voltage. Its variation allows to shift the desired resonance frequency included in the operating intervals of the acoustic resonator. The third device is a variable volume HR. Experimental results are presented to show the volume change effect on the resonance frequencies. All dimensions were chosen to allow the design of a characteristic acoustic treatment on a $100 \mathrm{~mm}$ diameter impedance tube. The proposed treatment combines a tunable $\mathrm{HR}$ (targeting low frequencies $<500 \mathrm{~Hz}$ ) and an ultralight melamine foam matrix (for medium and high frequencies $>500 \mathrm{~Hz}$ ). ${ }^{22}$

\section{FEM MODELING OF AN EAP-BASED HR}

The first study focuses on the FE modeling of the passive resonator HR1 (Fig.1 a). Acoustic properties defined by $\alpha$ are numerically investigated, based on the two microphones ${ }^{23}$ method. COMSOL software with Acoustic and Solid Mechanics packages was used ${ }^{24}$ to model the passive membraned HR embedded in a melamine foam (Fig.3). A plane wave is added as sound source at one end of the tube. The chosen frequency range of the impedance tube is $[10-1200] \mathrm{Hz}$.

\subsection{Mechanical modeling of the membrane}

The HR1 is a passive HR. The rigid front-wall is replaced by a $3 \mathrm{M}^{T M} \mathrm{VHB}^{T M} 4910$ acrylic membrane. The $3 \mathrm{M}$ Tape is $1 \mathrm{~mm}$ thick, acrylic adhesive on both sides. It offers powerful ability to deform to a variety of surfaces. In this study, this material is used to make circular membranes which are integrated as a component of a new kind of tunable HR.

Table 1. Geometrical dimensions of the studied devices

\begin{tabular}{|c|c|c|c|c|}
\hline & $\begin{array}{c}l_{\text {neck }} \\
(\mathrm{mm})\end{array}$ & $\begin{array}{c}r_{\text {neck }} \\
(\mathrm{mm})\end{array}$ & $\begin{array}{c}l_{\text {cavity }} \\
(\mathrm{mm})\end{array}$ & $\begin{array}{c}r_{\text {cavity }} \\
(\mathrm{mm})\end{array}$ \\
\hline $\mathrm{HR}$ & 15.7 & 6.75 & 70 & 30 \\
\hline
\end{tabular}


When the membrane is exited by an harmonic acoustic pressure $p e^{j \omega t}$, its out-of-plane vibration is governed by the following equation:

$$
T_{0} \nabla^{2} w(x, y)+\omega^{2} t_{m} \rho_{m} w(x, y)=\Delta p
$$

where $w(x, y)$ is the complex amplitude of the membrane displacement in the $\mathrm{z}$ direction; $T_{0}$ is the in-plane tension, $\rho_{m}$ is the material density and $t_{m}$ the membrane thickness.

The material was stretched three times on both directions making a stretch ratio of $\lambda=3$, which gave a thin membrane of $0.11 \mathrm{~mm}$ thick.

The inner stress of the pre-stretched membrane is given by:

$$
\sigma_{m}=T_{0} t_{m}
$$

Mechanical properties of the 3M VHB 4910 material $^{25}$ are listed in the Tab.2.

Table 2. 3M VHB 4910 mechanical properties

\begin{tabular}{|l|l|l|}
\hline $\begin{array}{l}\text { Shear modulus } \\
\mu(\mathrm{kPa})\end{array}$ & $\begin{array}{l}\text { Density } \\
\rho\left(\mathrm{kg}^{-3} \mathrm{~m}^{-3}\right)\end{array}$ & $\begin{array}{l}\text { Poisson's ratio } \\
\nu\end{array}$ \\
\hline 25 & 960 & 0.49 \\
\hline
\end{tabular}

\subsection{Acoustic model of the foam}

Johnson-Champoux-Allard model (JCA) model provides the expression of the dynamic compressibility $K(\omega)$ and the effective density $\rho(\omega)$ of the fluid saturating the porous medium ${ }^{26-28}$ using five intrinsic properties of the material; the flow resistivity $\sigma$, the porosity $\Phi$, the tortuosity $\alpha_{\infty}$, the viscous characteristic length $\Lambda$, and the thermal characteristic length $\Lambda^{\prime}$, given in Tab.3. It is used to model the melamine foam behavior and the viscous loss in the resonator neck. ${ }^{22}$

Table 3. Johnson-Champoux-Allard model parameters of the ultralight melamine foam

\begin{tabular}{|l|l|l|l|l|l|}
\hline & $\begin{array}{l}\sigma \\
\left(N . s . m^{-4}\right)\end{array}$ & $\Phi$ & $\alpha_{\infty}$ & $\begin{array}{l}\Lambda \\
(\mu m)\end{array}$ & $\begin{array}{l}\Lambda^{\prime} \\
(\mu m)\end{array}$ \\
\hline Foam & 8432 & 0.99 & 1.02 & 138 & 154 \\
\hline
\end{tabular}

The neck of the resonator is also modeled with JCA model in order to take into account the viscous losses related to the small diameter of the neck. The five JCA parameters are as follows:

$$
\begin{aligned}
\Phi_{\text {neck }} & =1 ; \\
\alpha_{\text {neck }} & =1 ; \\
\sigma_{\text {neck }} & =\frac{8 \eta}{r_{\text {neck }}^{2}} ; \eta: \text { Air viscosity } \\
\Lambda_{\text {neck }} & =r_{\text {neck }} ; \\
\Lambda_{\text {neck }}^{\prime} & =r_{\text {neck }} .
\end{aligned}
$$

In the case of absorption coefficient estimation, two microphones (referred as M1, and M2, in Fig.2) measure the acoustic pressure allowing to calculate the reflection coefficient $R$ using the transfer function method. The absorption coefficient $\alpha$ is then deducted from the reflection coefficient $R^{23}$.

$$
\alpha=1-|R|^{2}
$$




\subsection{Identification of the membrane tension}

In order to use the model, the value of the membrane tension $T_{0}$ must be known. An optimization process is used in order to identify its optimal value. All other parameters are known from Tab.1 and Tab.2.

Based on the computations of the absorption coefficient as a function of frequency $f r e q(\mathrm{~Hz})$, and given $N$ pairs of measurements $\left(\alpha_{i}\right.$, freq $\left._{i}\right), i=1 . . N$, the values of the model parameters which best fit the measured data are considered to be those which minimize the total squared error $e$ based on the following equation:

$$
e=\sum_{i=1}^{N}\left(\alpha\left(\text { freq }_{i}\right)-\alpha_{i}\right)^{2}
$$

The LMS (Least Mean Square) algorithm ${ }^{29}$ is used to identify the membrane in-plane tension $T_{0}$.

\section{EXPERIMENTAL SETUP}

Three different Helmholtz resonator configurations based on the same geometrical dimensions given in Tab.1 are studied: a passive front-wall membrane HR referred as HR1 (Fig.1 a), an Electroactive membraned resonator HR2 (Fig.1 b) and a variable volume resonator HR3 (Fig.1 c). The resonators are integrated in a cylindrical melamine foam matrix. A loudspeaker installed in a $100 \mathrm{~mm}$ diameter tube generates a white noise wave. In order to power the EAP membrane, a $N I-6009$ A/D converter $(0-5 \mathrm{~V})$ controls a DC high voltage converter generating 0 to $5 \mathrm{kV}$ (Fig.2).

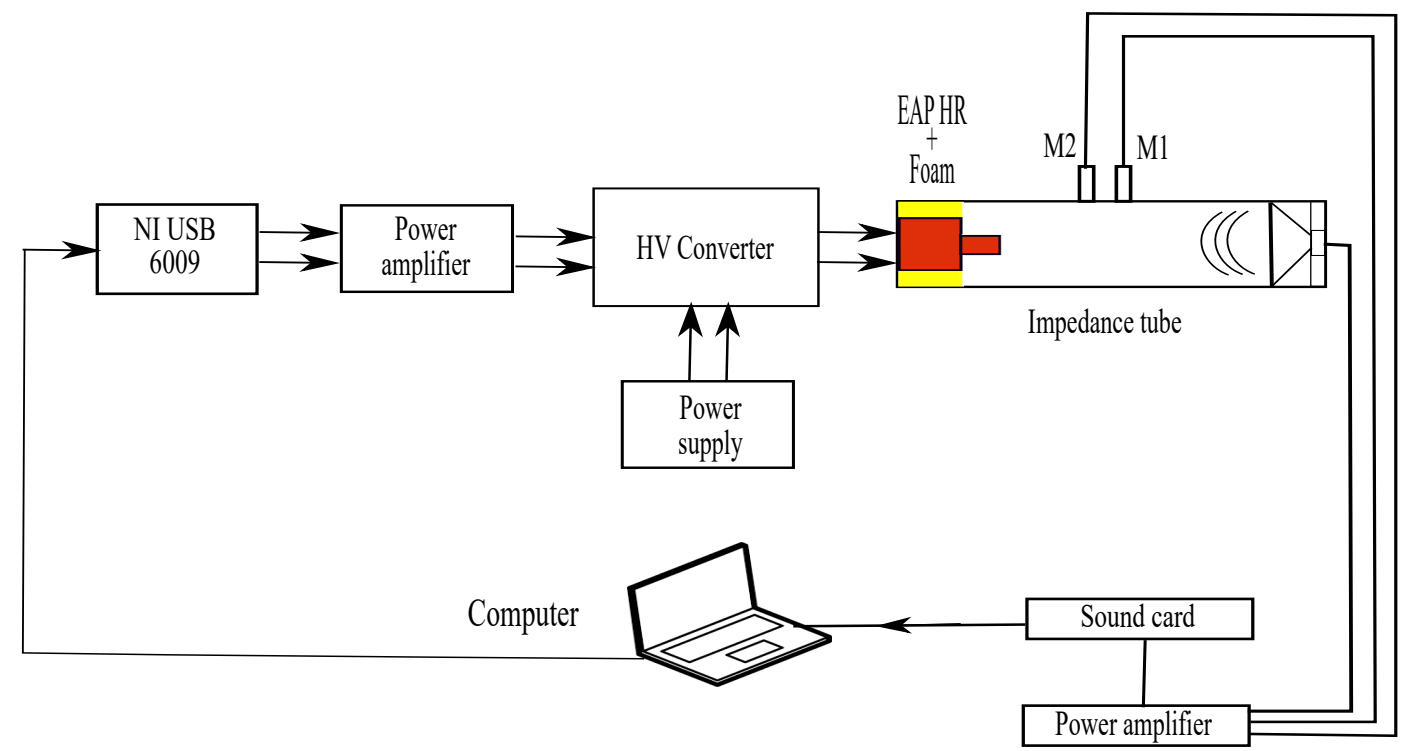

Figure 2. Experimental setup for the tunable resonators characterization using an impedance tube

The two microphones method is used to determine $\alpha$. Acoustic data acquisitions were operated by a sound card (Focusrite 18i20) on the frequency range of $[10-1200] \mathrm{Hz}$.

\section{RESULTS}

\subsection{Passive Helmholtz resonator (HR1)}

The front rigid wall of the rigid HR is replaced by an EAP membrane as shown in Fig.1 (a). Dimensions are listed in Tab.1. The cylindrical cavity is $70 \mathrm{~mm}$ depth and $30 \mathrm{~mm}$ radius. The dimensions of the circular membrane are $30 \mathrm{~mm}$ radius and $0.11 \mathrm{~mm}$ thickness.

A FEM model combined with an optimization process is used to fit the experimental results. The acoustic 
pressure $(\mathrm{Pa})$ computed in the system at a frequency of $f=200 \mathrm{~Hz}$ (which corresponds to the first resonance frequency) is shown in Fig.3.

\section{$\mathrm{TO}(1)=37 \mathrm{~N} / \mathrm{m}$ freq $(15)=200 \mathrm{~Hz}$ Surface: Total acoustic pressure field $(\mathrm{Pa})$}

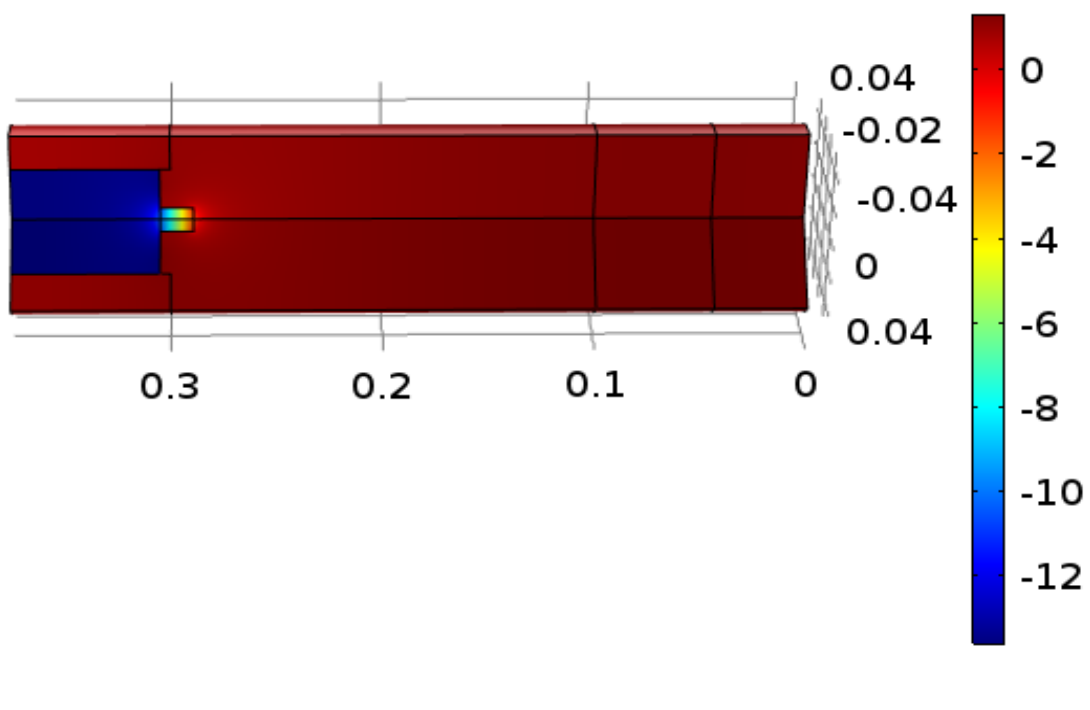

Figure 3. Sound pressure level obtained from the FEM model of HR1 embedded in a melamine foam

At this frequency, the acoustic pressure observed inside the HR1 is way less than in the rest of the tube, demonstrating, thus, the ability of the device to attenuate certain frequencies.

In Fig.4, numerical and experimental absorption coefficient $(\alpha)$ curves are compared. The value of the in-plane tension $T_{0}$ that fits best the experimental data is $T_{0}=37 \mathrm{~N} / \mathrm{m}$.

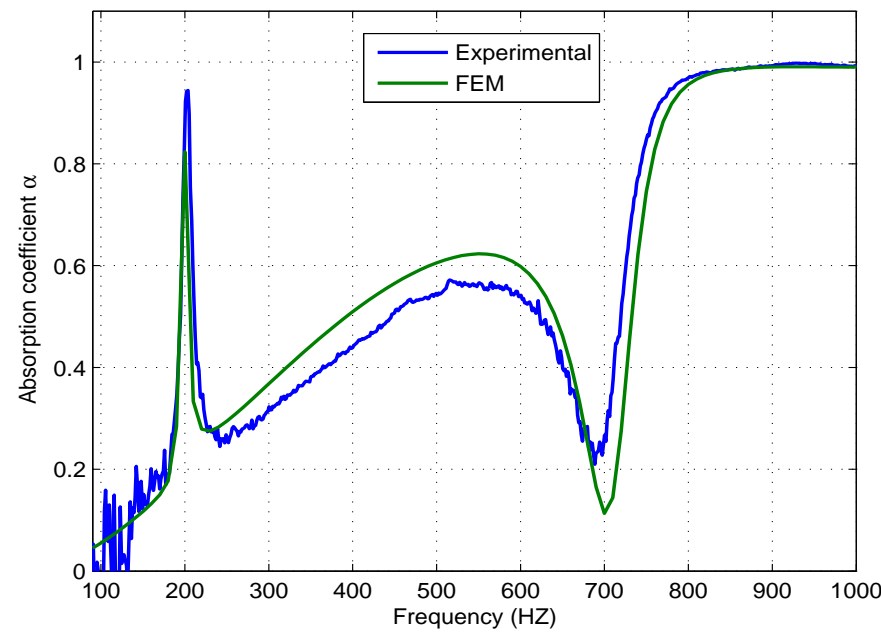

Figure 4. Experimental and fitted curves comparison: $\alpha$ of the passive Helmholtz resonator HR1 
The Acoustic device depicts two main peaks at the resonance frequencies of the resonator. The first one is around $f_{r e s}=206 \mathrm{~Hz}$. It corresponds to the classical Helmholtz resonance, while the second arising around $f_{r e s}=700 \mathrm{~Hz}$ is a membrane resonance. ${ }^{30}$ The FE model agrees well with experimental curves in terms of general tendencies as well as resonance locations. Yu used the same material and stretch ration in, ${ }^{21}$ he advocates a $T 0=24.4 \mathrm{~N} / \mathrm{m}$. The obtained deviation could be explained by the experimental errors due to the manufacturing process of the membrane, the mounting of the neck ( Not used in Yu's work)and its bonding supports.

Instead of a classical Helmholtz resonator which is known to depict a single principal resonance, ${ }^{22}$ the proposed one depicts two resonances. Since the mechanical behavior of the membrane may be tuned by the voltage applied between the electrodes, it must be concluded that placing the EAP membrane on the front part of the resonator seems to have a good potential to tune the resonator to low frequencies.

\subsection{Active Helmholtz resonator (HR2)}

A carbon powder is used as electrodes of the membrane. The applied electric voltage varies from 0 to $4000 \mathrm{~V}$. The resonator is embedded in an ultralight melamine foam. The sound absorption $(\alpha)$ under variation of voltage is investigated. This analysis is performed in an open-loop.

Absorption coefficient of the HR2 are shown in Fig.5. The applied voltage on the EAP membrane changes its stiffness and therefore its mechanical and acoustical properties.

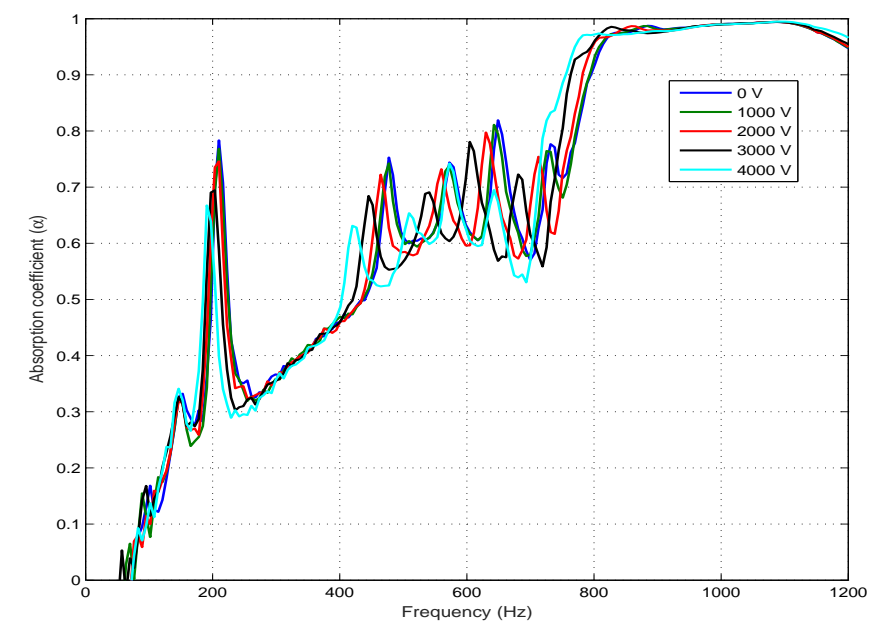

Figure 5. Effect on the absorption coefficient $(\alpha)$ under an actuation voltage of 0 to $4000 \mathrm{~V}$ in the case of HR2

Fig.5 shows several peaks in the case of HR2. In the case of $0 \mathrm{~V}$ voltage (blue curve) in Fig.5, the first resonance frequency is around $f_{\text {res }}=210 \mathrm{~Hz}$ and $80 \%$ absorption. The other following resonances in the interval [600 - 1000] $\mathrm{Hz}$ are fairly clear with an amplitude up to $19 \mathrm{~dB}$ in the case of $4000 \mathrm{~V}$ are membrane resonances. Helmholtz resonance frequencies resulting from the various applied voltages are listed in Tab.4.

Table 4. First resonance frequency as function of the applied voltage in the case of HR2

\begin{tabular}{|l|l|l|l|l|l|}
\hline Res.freq|Voltage & $0 \mathrm{kV}$ & $1 \mathrm{kV}$ & $2 \mathrm{kV}$ & $3 \mathrm{kV}$ & $4 \mathrm{kV}$ \\
\hline$f_{\text {res } 1}[\mathrm{~Hz}]$ & 210 & 207 & 203 & 197 & 190 \\
\hline
\end{tabular}

The resonance shift phenomenon is shown in Fig.6. The change operates as a function of the applied voltage. Both Helmholtz and membrane resonance peaks decrease to lower frequencies when voltage increases. 


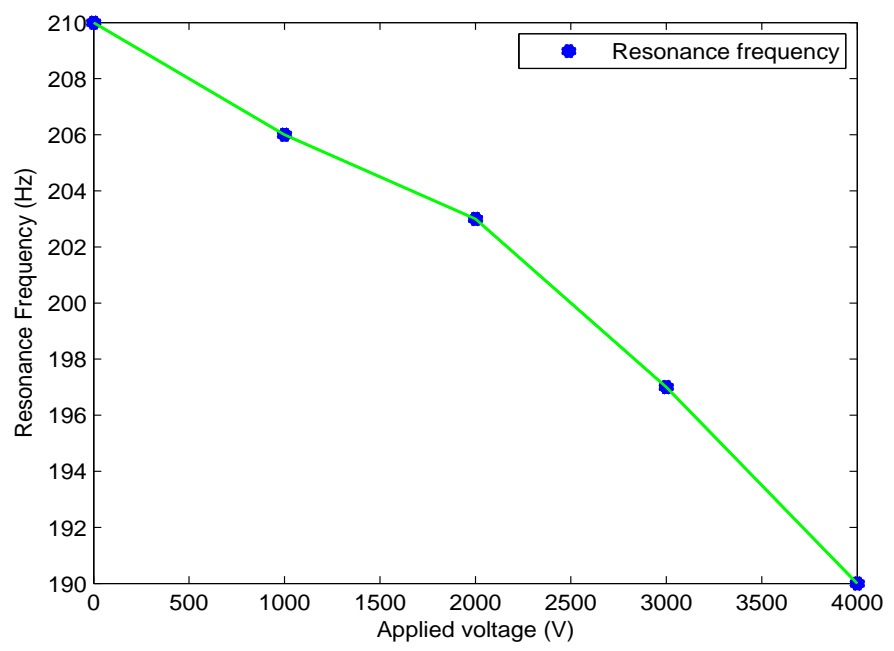

Figure 6. Resonance frequency as a function of the applied voltages variation for HR2

The peak shifts can be explained by considering the interactions between the membrane stiffness variation and the Helmholtz cavity resonances. A $10 \%$ variation in resonance frequency is obtained for $4000 \mathrm{~V}$. $\alpha$ shift mechanism is then found to be able to be controlled by the membrane resonance resulting from the change in its inner stress.

\subsection{Variable Volume Helmholtz resonator (HR3)}

For HR3 shown in Fig.1(c), a spring is placed inside the resonator cavity, which applies additional prestressing to the membrane making a potential variable volume HR. A change in volume ranging from $20 \%$ to $30 \%$ is targeted by this concept. It is expected that a change in volume combined with a change in the membrane stiffness would allow a wider control of the frequency band of the resonator.

The applied voltage varies from 0 to $3000 \mathrm{~V}$. It makes the membrane move following an axial deformation ( $\mathrm{z}$ direction). An added volume is created, which changes the resonator acoustic performances. Variations on the sound absorption coefficient is obtained as shown in Fig.7.

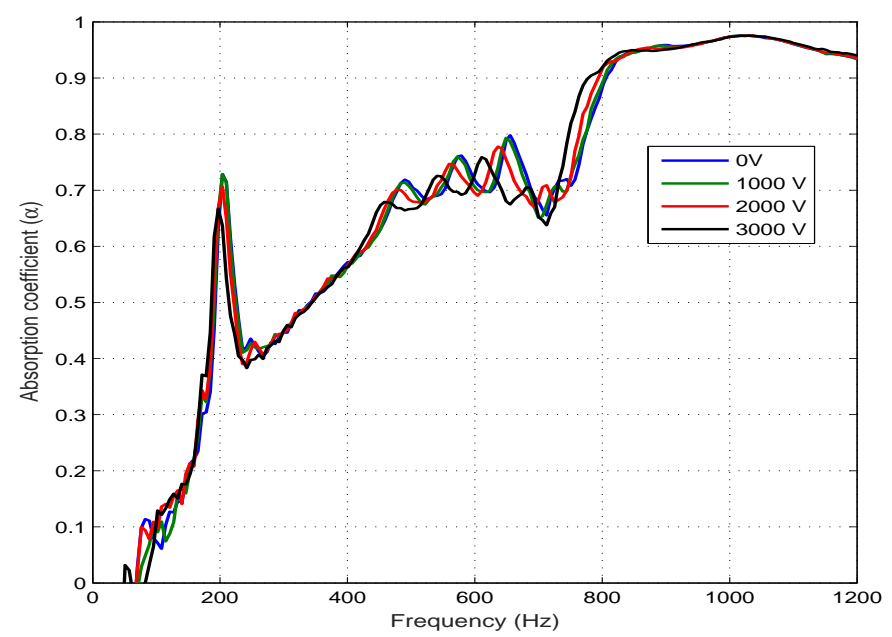

Figure 7. Effect on the absorption coefficient under an actuation voltage of 0 to $3000 \mathrm{~V}$ in the case of the HR3 
In the case of $0 \mathrm{~V}$ voltage (Fig.7; blue curve), the first resonance frequency is about $f_{\text {res }}=208.7 \mathrm{~Hz}$ and $73 \%$ absorption ratio.

Table 5. Resonance frequencies vs applied voltage in the case of the Variable volume HR3

\begin{tabular}{|l|l|l|l|l|}
\hline Res.freq|Voltage & $0 \mathrm{kV}$ & $1 \mathrm{kV}$ & $2 \mathrm{kV}$ & $3 \mathrm{kV}$ \\
\hline$f_{\text {res } 1}[\mathrm{~Hz}]$ & 208.7 & 206 & 201.3 & 196.8 \\
\hline
\end{tabular}

The resonance shift (Fig.7) is obtained from the volume variation due to the applied voltage. The Helmholtz and membrane resonance peaks decrease to lower frequencies when voltage increases. It is observed that the amplitude of the obtained peaks in the case of the HR3 decrease compared to HR2.

The spring allows a volume variation of the resonator (approximately 5 to $10 \%$ ). The applied voltage in the presented case varies between 0 and $3000 \mathrm{~V}$. The first resonance frequency is around $208.7 \mathrm{~Hz}$ for the HR3 whereas $210 \mathrm{~Hz}$ in the case of HR2. The same decrease trend is observed for the other frequencies when the voltage changes.

Higher voltage $(>5000 \mathrm{~V})$ will make a bigger volume. Larger shift in resonance can be observed.

\section{CONCLUSIONS}

Numerical and experimental results have shown the effects of the integration of a polymer acrylic membrane and their potential to modify the Helmholtz resonator behavior. An EAP membrane is then used to tune the resonators. The integration of the active membrane helps to vary the resonance at low frequencies by varying the applied voltage. A $20 \%$ shift is then obtained for $4000 \mathrm{~V}$. In addition, other resonance peaks are observed at higher frequencies. This may be beneficial to improve the device Transmission Loss effect. Well located spring shows a real potential to make a variable volume Helmholtz resonator.

Future work will focus on the development of a more complex model taking into account all involved physics in order to define the real potential of a real time adaptive Helmholtz resonator based on the volume variation process.

\section{REFERENCES}

[1] Ingard, U., "On the theory and design of acoustic resonators," The Journal of the acoustical society of America 25(6), 1037-1061 (1953).

[2] Hughes, I. and Dowling, A., "The absorption of sound by perforated linings," Journal of Fluid Mechanics 218, 299-335 (1990).

[3] Chanaud, R., "Effects of geometry on the resonance frequency of helmholtz resonators," Journal of Sound and Vibration 178(3), 337-348 (1994).

[4] Allard, J. and Atalla, N., [Propagation of Sound in Porous Media: Modelling Sound Absorbing Materials 2e], John Wiley \& Sons (2009).

[5] Kanoi, M., Hori, Y., Maejima, M., and Obata, T., "Transformer noise reduction with new sound insulation panel," tech. rep., Hitachi Research Lab., Hitachi, Ltd. Hitachi City, Ibaraki Prefecture (1983).

[6] Kiyota, Y., Asai, M., Sugita, H., and Akiyama, A., "Low frequency noise reduction by improving sound insulation materials," tech. rep., SAE Technical Paper (1995).

[7] Wen-chao, H. and Chung-fai, N., "Sound insulation improvement using honeycomb sandwich panels," Applied Acoustics 53(1-3), 163-177 (1998).

[8] Prydz, R., Wirt, L., Kuntz, H., and Pope, L., "Transmission loss of a multilayer panel with internal tuned helmholtz resonators," The Journal of the Acoustical Society of America 87(4), 1597-1602 (1990).

[9] Kim, S., Kim, Y.-H., and Jang, J.-H., "A theoretical model to predict the low-frequency sound absorption of a helmholtz resonator array," The Journal of the Acoustical Society of America 119(4), 1933-1936 (2006).

[10] Mason, J. and Fahy, F., "The use of acoustically tuned resonators to improve the sound transmission loss of double-panel partitions," Journal of Sound and Vibration 124(2), 367-379 (1988). 
[11] Kuntz, H. L., Gatineau, R., Prydz, R., and Balena, F., "Development and testing of cabin sidewall acoustic resonators for the reduction of cabin tone levels in propfan-powered aircraft," (1991).

[12] De Bedout, J. M., Adaptive-passive noise control with self-tuning Helmholtz resonators, PhD thesis, Citeseer (1996).

[13] Horowitz, S. B., Design and characterization of compliant backplate Helmholtz resonators, PhD thesis, University of Florida (2001).

[14] Ruan, D.-F. and Zhang, E.-Y., "Effect of compliant-diaphragm geometry on the transmission loss characteristics of helmholtz resonators," Noise \& Vibration Worldwide 45(11), 9-15 (2014).

[15] Pelrine, R., Kornbluh, R., and Kofod, G., "High-strain actuator materials based on dielectric elastomers," Advanced Materials 12(16), 1223-1225 (2000).

[16] Brochu, P. and Pei, Q., "Advances in dielectric elastomers for actuators and artificial muscles," Macromolecular rapid communications 31(1), 10-36 (2010).

[17] Monner, H., "Smart materials for active noise and vibration reduction," NOVEM: Noise and Vibration: Emerging Methods, Saint-Raphal, France (2005).

[18] Zhao, X. and Suo, Z., "Theory of dielectric elastomers capable of giant deformation of actuation," Physical review letters 104(17), 178302 (2010).

[19] Lu, Z., Godaba, H., Cui, Y., Foo, C. C., Debiasi, M., and Zhu, J., "An electronically tunable duct silencer using dielectric elastomer actuators," The Journal of the Acoustical Society of America 138(3), EL236EL241 (2015).

[20] Yu, X., Lu, Z., Cui, F., Cheng, L., and Cui, Y., "Tunable acoustic metamaterial with an array of resonators actuated by dielectric elastomer," Extreme Mechanics Letters (2016).

[21] Yu, X., Lu, Z., Cheng, L., and Cui, F., "Vibroacoustic modeling of an acoustic resonator tuned by dielectric elastomer membrane with voltage control," Journal of Sound and Vibration 387, 114-126 (2017).

[22] Doutres, O., Atalla, N., and Osman, H., "Modeling and experimental validation of cellular porous material with large resonant inclusions," in [Inter-noise and noise-CON Congress and conference proceedings], 249(7), 1228-1235, Institute of Noise Control Engineering (2014).

[23] Chung, J. and Blaser, D., "Transfer function method of measuring in-duct acoustic properties. ii. experiment," The Journal of the Acoustical Society of America 68(3), 914-921 (1980).

[24] "Comsol multiphysics acoustic module-users guide," (2013).

[25] 3M Industrial Adhesives and Tapes Division, 3M VHB Tape Specialty Tapes (2015).

[26] Marec, A. and Salvucci, A., Identification des paramtres acoustiques intinsques de matriaux de l'environnement partir de la mesure in situ d'absorption acoustique, Master's thesis, ENSI Mans (2004).

[27] Champoux, Y. and Allard, J.-F., "Dynamic tortuosity and bulk modulus in air-saturated porous media," Journal of Applied Physics 70(4), 1975-1979 (1991).

[28] Allard, J.-F. and Champoux, Y., "New empirical equations for sound propagation in rigid frame fibrous materials," The Journal of the Acoustical Society of America 91(6), 3346-3353 (1992).

[29] Hyvärinen, A., Karhunen, J., and Oja, E., [Independent component analysis], vol. 46, John Wiley \& Sons (2004).

[30] Abbad, A., "Numerical investigations on a tunable helmholtz resonator: Integration of a passive polymer membrane in a helmholtz resonator," tech. rep., SAE Technical Paper (2016).

\section{Acknowledgments}

Je ne sais pas s'il est toujours valable d'crire a sur cette partie:

The authors would like to thank the National Sciences and Engineering Research Council of Canada (NSERC) for providing financial support. It has been performed in cooperation with the project ANR-12-JS09-008-COVIA and the Labex ACTION program (ANR-11-LABX-0001-01). 